\title{
Diversity of Fusarium species and mycotoxins contaminating pineapple
}

\author{
Lukasz Stępień • Grzegorz Koczyk • \\ Agnieszka Waśkiewicz
}

Received: 21 January 2013 /Revised: 11 March 2013 / Accepted: 12 March 2013 / Published online: 10 April 2013

(C) The Author(s) 2013. This article is published with open access at Springerlink.com

\begin{abstract}
Pineapple (Ananas comosus var. comosus) is an important perennial crop in tropical and subtropical areas. It may be infected by various Fusarium species, contaminating the plant material with mycotoxins. The aim of this study was to evaluate Fusarium species variability among the genotypes isolated from pineapple fruits displaying fungal infection symptoms and to evaluate their mycotoxigenic abilities. Forty-four isolates of ten Fusarium species were obtained from pineapple fruit samples: $F$. ananatum, $F$. concentricum, F. fujikuroi, F. guttiforme, F. incarnatum, $F$. oxysporum, $F$. polyphialidicum, $F$. proliferatum, $F$. temperatum and $F$. verticillioides. Fumonisins $\mathrm{B}_{1}-\mathrm{B}_{3}$, beauvericin (BEA) and moniliformin (MON) contents were quantified by high-performance liquid chromatography (HPLC) in pineapple fruit tissue. Fumonisins are likely the most dangerous metabolites present in fruit samples (the maximum $\mathrm{FB}_{1}$ content was $250 \mu \mathrm{g} \mathrm{g}^{-1}$ in pineapple skin and $20 \mu \mathrm{g} \mathrm{ml}^{-1}$ in juice fraction). In both fractions, BEA and MON were of minor significance. FUM1 and FUM8 genes were identified in F. fujikuroi, $F$. proliferatum, $F$. temperatum and $F$. verticillioides. Cyclic peptide synthase
\end{abstract}

Electronic supplementary material The online version of this article (doi:10.1007/s13353-013-0146-0) contains supplementary material, which is available to authorized users.

Ł. Stępień $(\square)$

Department of Pathogen Genetics and Plant Resistance, Institute of Plant Genetics, Polish Academy of Sciences, Strzeszyńska 34, 60-479 Poznań, Poland

e-mail: 1ste@igr.poznan.pl

G. Koczyk

Department of Biometry and Bioinformatics, Institute of Plant Genetics, Polish Academy of Sciences, Strzeszyńska 34, 60-479 Poznań, Poland

A. Waśkiewicz

Department of Chemistry, Poznań University of Life Sciences, Wojska Polskiego 75,

60-625 Poznań, Poland gene (esyn1 homologue) from the BEA biosynthetic pathway was identified in 40 isolates of eight species. Based on the gene-specific polymerase chain reaction (PCR) assays, none of the isolates tested were found to be able to produce trichothecenes or zearalenone.

Keywords Ananas comosus $\cdot F U M$ genes $\cdot$ Mycotoxins · Phylogeny $\cdot$ Tropical fruit diseases

\section{Introduction}

Pineapple [Ananas comosus (L.) Merr. var. comosus, syn. Ananas ananas (L.) Voss] is a crop native to tropical and subtropical areas of South America, where it holds a considerable economic importance (Ploetz 2001). This perennial plant is susceptible to a number of fungal diseases, of which fusariosis is the most severe. The disease affects almost all parts of the plant, damaging particularly fruit and stem apices. However, the agent causing the disease is ambiguous and other diseases caused by Fusarium fungi (like fruitlet core rot) have also been reported (Ploetz 2006). As a result of the systemic dispersal inside the host plant, many members of the Fusarium genus have the ability of colonising perennial crops with only scarce symptoms of infection while still being detectable (de Oliveira Rocha et al. 2011; Weber et al. 2006). Moreover, even in the case of an asymptomatic infection, significant mycotoxin contamination of the plant tissues is possible (Desjardins 2006; Stankovic et al. 2007; Thiel et al. 1992; von Bargen et al. 2009). Fusarium guttiforme has been frequently associated with pineapple fusariosis in Brazil (Ploetz 2006), while $F$. subglutinans emerged as the main cause associated with fruitlet core rot in Hawaii (Rohrbach and Pfeiffer 1976). Both species belong to the Gibberella fujikuroi species complex (GFSC); however, F. subglutinans is currently not regarded as a pineapple pathogen (Leslie and Summerell 
2006). More recently, a novel species infecting pineapple and originating from South Africa was characterized as $F$. ananatum. The new pathogenic species was found to be closely related to both $F$. subglutinans and $F$. guttiforme (Jacobs et al. 2010). The geographical incidence of those species, as well as their host species range, is still to be determined. It has been demonstrated that, for some pathogens (like $F$. oxysporum and $F$. subglutinans), a considerable level of host-pathogen specificity was developed (Lievens et al. 2007; Steenkamp et al. 1999; Sutherland and Pegg 1992). Recently, Boutigny et al. (2011) found some evidence that members of the Gibberella zeae species complex also exhibit host preference to some extent. The analysis of the tef- $1 \alpha$ sequence is widely used to infer phylogenetic relationships between closely related genotypes (e.g. Jurado et al. 2010; Kristensen et al. 2005; Moretti et al. 2008; Punja et al. 2008; Stępień et al. 2011a, 2011b, 2012). In addition to the tef- $1 \alpha$ sequence, the sequencing of other polymorphic regions like $\beta$-tubulin, MAT alleles, H3 histone, cellobiohydrolase-C $(c b h-C)$ and topoisomerase II (topII) has become increasingly useful for the molecular identification of Fusaria (Hatsch et al. 2004; Jacobs et al. 2010; O'Donnell et al. 2004; Steenkamp et al. 1999).

To date, there is little information on secondary metabolites produced by Fusaria in infected pineapple plants. Based on the in vitro and also in planta mycotoxin synthesis comparison of the GFSC, one should consider moniliformin (MON), beauvericin (BEA), fumonisins, fusaproliferin, fusarins and fusaric acid as likely major metabolites (Kvas et al. 2009). The fumonisin biosynthetic pathway has been well recognized and described (Proctor et al. 2006) and FUM genes (particularly FUM1) have often been used for studies of fumonisinproducing fungi (Khaldi and Wolfe 2011; Proctor et al. 2008; Stępień et al. 2011a; Waalwijk et al. 2004). Recently, the structure of the BEA biosynthetic gene cluster in $F$. proliferatum has been revealed (Zhang et al. 2012). Moreover, two clusters responsible for the synthesis of fusarins and fusaric acid by $F$. verticillioides have been elucidated (Brown et al. 2012). The progress in the studies focused on the Fusarium secondary metabolite biosynthetic pathways has been recently summarized (Stępień 2013).

Fusarium proliferatum is able to synthesize many of the mycotoxins produced by the members of the Fusarium genus. Although, until now, the species was not regarded as a pineapple pathogen (Jacobs et al. 2010; Ploetz 2006), nevertheless, the worldwide distribution of this polyphagous and cosmopolitan species (Kenényi et al. 2002; Jurado et al. 2010) may implicate that its occurrence on pineapple is possible and some isolates have already been described (Stępień et al. 2011a; 2011b). In consequence, a broad range of Fusarium mycotoxins would likely occur in pineapple tissues. This group includes fumonisins, which, together with trichothecenes and zearalenone, are regarded as the most dangerous to animal and human health (Desjardins 2006).

The two main aims of this study were to evaluate the species variability of Fusarium isolates obtained from pineapple fruit with fungal infection symptoms and to examine their mycotoxigenic potential. The latter was done by (i) quantitative analyses of fumonisins, BEA and MON present in pineapple tissue samples and (ii) identifying essential genes of fumonisin, trichothecene, zearalenone and BEA/enniatin metabolic pathways using gene-specific polymerase chain reaction (PCR) assays.

\section{Materials and methods}

\section{Fusarium strains purification}

Plant material consisted of commercially available pineapple fruit originating from Costa Rica, Ecuador, Honduras and Hawaii. Additionally, some fruit samples from Indonesia (IN) and Vietnam (VN) were collected directly from the local market in a pineapple breeding area. The pineapple fruits were examined for the presence of Fusarium fungi over the course of a 3-year survey. Pieces of fruit tissue were cut out of the pineapple fruit core and plated on potato dextrose agar (PDA) medium. The core is usually the part where mycelia of the contaminating fungi occur first. After a few days of incubation at room temperature, the tips of single hyphae of all Fusarium fungi were transferred onto new plates. The obtained fungal strains were passaged onto fresh PDA plates the same way at least three times to assure their purity. For most of the isolates, single spore cultures were performed according to Leslie and Summerell (2006). All isolates are deposited in the KF Fusarium collection at the Institute of Plant Genetics, Polish Academy of Sciences, Poznań, Poland.

\section{Colony growth rate measurement}

The growth speed of 31 Fusarium isolates was measured as the diameter of fungal colonies on 90-mm Petri plates with PDA medium (Oxoid, Basingstoke, Hampshire, UK) following 7 days of incubation in 24-h intervals, replicated twice. The temperature of $25^{\circ} \mathrm{C}$ was chosen, as it appeared to be the optimum for differentiation between fast- and slow-growing Fusarium strains in previous studies (Stępień et al. 2011b). The mean values were calculated and presented.

DNA extraction, primers, PCR assays and DNA sequencing

Mycelia of the isolates studied were grown on solid PDA medium to control and eliminate any bacterial or fungal 
contaminations. They were harvested after 7 days and stored at $-20{ }^{\circ} \mathrm{C}$. Genomic DNAs of all isolates were extracted using a hexadecyltrimethylammonium bromide (CTAB) method, as described previously (Stępień et al. 2004), and the DNA concentrations were adjusted to $10 \mathrm{ng} \mu \mathrm{l}^{-1}$. All the primer details are presented in Table 1. Some of the primers used for PCR assays were designed with Primer3 and PrimerBlast software using sequences of biosynthetic genes deposited in the NCBI GenBank, while others, like tef- $1 \alpha$, were previously published and validated. The $25-\mu 1$ reaction volume consisted of 1 unit of Platinum HotStart Taq DNA polymerase (Invitrogen, Carlsbad, CA, USA), $1 \times$ PCR buffer, $12.5 \mathrm{pmol}$ of each forward and reverse primers, $2.5 \mathrm{mmol}^{-1}$ of each dNTPs and 10-20 ng of genomic DNA as template. The PCR conditions were as follows: 15 min at $95{ }^{\circ} \mathrm{C}, 35$ cycles of $\left(30-60 \mathrm{~s}\right.$ at $94{ }^{\circ} \mathrm{C}, 30-60 \mathrm{~s}$ at $58-63{ }^{\circ} \mathrm{C}, 1-2 \mathrm{~min}$ at $72{ }^{\circ} \mathrm{C}$ ) and $10 \mathrm{~min}$ at $72{ }^{\circ} \mathrm{C}$ (see Table 1 for annealing temperatures). Amplicons were electrophoresed in $1.5 \%$ agarose gels (Invitrogen) with ethidium bromide staining and visualised using UV light.

Fragments of tef- $1 \alpha, F U M 1$ and FUM 8 genes obtained with the Fum1F1/R2 and Antfum8F/R primers were sequenced. Prior to the sequencing reaction, PCRamplified DNA fragments were purified using exonuclease I (Epicentre, Madison, WI, USA) and shrimp alkaline phosphatase (Promega, Madison, WI, USA) using the following program: $30 \mathrm{~min}$ at $37{ }^{\circ} \mathrm{C}$, followed by $15 \mathrm{~min}$ at $80{ }^{\circ} \mathrm{C}$. Both strands were labelled using the BigDye Terminator v3.1 kit (Applied Biosystems, Foster City, CA, USA) and purified by ethanol precipitation according to the procedure outlined by Błaszczyk et al. (2004). Sequence reading was performed using Applied Biosystems 3130 equipment.

Sequence analysis and phylogeny reconstruction

In order to evaluate the phylogenetic relationships between the isolates studied, multiple alignments of tef- $1 \alpha, F U M 1$ and FUM8 sequences were created with ClustalW (Larkin et al. 2007). Subsequently, they were realigned separately for intron and exon regions using MUSCLE (Edgar 2004) and edited in SEAVIEW (Gouy et al. 2010). Phylogenetic relationships were reconstructed using MEGA4 (Tamura et al. 2007). All gene sequences were analyzed using the maximum parsimony approach (closest neighbour interchange heuristics), with complete deletion (i.e. no positions containing gaps were considered in the phylogeny analysis). All reconstructions were validated by bootstrapping with 1,000 replicates.

Aligned sequences of the translation elongation factor tef- $1 \alpha$ (alignment length of $427 \mathrm{bp}$ ) from tested strains were compared to the reference sequences deposited in the NCBI

Table 1 Target genes amplified by polymerase chain reaction (PCR), primer sequences, annealing temperatures (Tm), expected amplicon sizes, GenBank accessions numbers and references

\begin{tabular}{|c|c|c|c|c|c|}
\hline Target gene & Primers & $5^{\prime}>3^{\prime}$ sequence & $\operatorname{Tm}\left({ }^{\circ} \mathrm{C}\right) /$ exp. size & GenBank acc. & References \\
\hline tef $-1 \alpha$ & $\begin{array}{l}\text { Ef728M } \\
\text { Tef1R }\end{array}$ & $\begin{array}{l}\text { CATCGAGAAGTTCGAGAAGG } \\
\text { GCCATCCTTGGAGATACCAGC }\end{array}$ & $\begin{array}{l}63 \\
\sim 600\end{array}$ & Multiple & Stępień et al. (2011a) \\
\hline FUM1 & $\begin{array}{l}\text { Fum1F1 } \\
\text { Fum1R2 }\end{array}$ & $\begin{array}{l}\text { CACATCTGTGGGCGATCC } \\
\text { ATATGGCCCCAGCTGCATA }\end{array}$ & $\begin{array}{l}62.5 \\
1,126\end{array}$ & AF155773 & Stępień et al. (2011a) \\
\hline FUM8 & $\begin{array}{l}\text { Antfum8F } \\
\text { Antfum8R }\end{array}$ & $\begin{array}{l}\text { ACGGCTCTCCCGTTGTCTGC } \\
\text { GGCCAGCCGTCTCTCAAGCG }\end{array}$ & $\begin{array}{l}60 \\
651\end{array}$ & AY577456 & Stępień et al. (2011a) \\
\hline PKS4 & $\begin{array}{l}\text { PKS4_F } \\
\text { PKS4_R }\end{array}$ & $\begin{array}{l}\text { AGACGGCGCAACAAGGGCTG } \\
\text { GCAGTTGCCCGTGTCGGACA }\end{array}$ & $\begin{array}{l}60 \\
355\end{array}$ & AY495638.1 & Stępień et al. (2012) \\
\hline PKS13 & $\begin{array}{l}\text { PKS13_1 } \\
\text { PKS13_2 }\end{array}$ & $\begin{array}{l}\text { CCCAGCCAAGCCCAGTACGC } \\
\text { ACAGCGGCTGACCTGGGTCA }\end{array}$ & $\begin{array}{l}60 \\
532\end{array}$ & DQ019316.1 & Stępień et al. (2012) \\
\hline TRI5 & $\begin{array}{l}\text { TRI5_1 } \\
\text { TRI5_2 }\end{array}$ & $\begin{array}{l}\text { AGCGACTACAGGCTTCCCTC } \\
\text { AAACCATCCAGTTCTCCATCT }\end{array}$ & $\begin{array}{l}62 \\
545\end{array}$ & EF661664.1 & Stępień et al. (2011a) \\
\hline TRI13 & $\begin{array}{l}\text { TRI13_NIVF } \\
\text { TRI13_NIVR }\end{array}$ & $\begin{array}{l}\text { CCAAATCCGAAAACCGCAG } \\
\text { TTGAAAGCTCCAATGTCGTG }\end{array}$ & $\begin{array}{l}58 \\
290\end{array}$ & AY057841.1 & Nicholson et al. (2004) \\
\hline TRI13 & $\begin{array}{l}\text { TRI13_DONF } \\
\text { TRI13_DONR }\end{array}$ & $\begin{array}{l}\text { CATCATGAGACTTGTKCRAGT } \\
\text { GCTAGATCGATTGTTGCATTGAG }\end{array}$ & $\begin{array}{l}58 \\
225\end{array}$ & AF336366.2 & Nicholson et al. (2004) \\
\hline esyn1 & $\begin{array}{l}\text { Esyn_1 } \\
\text { Esyn_2 }\end{array}$ & $\begin{array}{l}\text { GCCGTTGGCGAGCTGGTCAT } \\
\text { GCAAAGCACGCGTCAACGCA }\end{array}$ & $\begin{array}{l}60 \\
997\end{array}$ & Z18755.3 & $\begin{array}{l}\text { Stępień and Waśkiewicz } \\
\text { (2013) }\end{array}$ \\
\hline bsyn 1 & $\begin{array}{l}\text { beas_1 } \\
\text { beas_2 }\end{array}$ & $\begin{array}{l}\text { TKGARCAGCGBCAYGAGACM } \\
\text { GGWCGRGGGAARTCRGTDGG }\end{array}$ & $\begin{array}{l}58 \\
495\end{array}$ & Multiple $^{\mathrm{a}}$ & $\begin{array}{l}\text { Stępień and Waśkiewicz } \\
\text { (2013) }\end{array}$ \\
\hline
\end{tabular}

${ }^{a}$ Based on consensus sequence elucidated from three NCBI database sequences and three unpublished sequences obtained by the authors in preliminary experiments 
GenBank using the BLASTN algorithm for species identification. Fourteen reference strains were also included in the phylogenetic reconstruction: F. solani FGSC 9596 (NECHADRAFT 59329), F. graminearum NRRL 31084 (FGSG_08811), F. oxysporum f. sp. lycopersici NRRL 34936 (FOXG 03515), F. verticillioides FGSC 7600 (FVEG 02381), F. ananatum NRRL 53131 (HM347128), F. begoniae NRRL 25300 (AF160293), F. bulbicola NRRL 13618 (AF160294), F. concentricum NRRL 26434 (AF333933), F. guttiforme ITEM 7611 (JN092343), F. guttiforme NRRL 22945 (AF160297; re-identified as $F$. ananatum by Jacobs et al. 2010), F. guttiforme MRC 6782 (DQ282170), F. guttiforme MRC 7539 (DQ282165), F. subglutinans MUCL 52468 (HM067691), F. succisae NRRL 13613 (AF160291), F. temperatum MUCL 52462 (HM067690). The reference sequences for F. graminearum, $F$. verticillioides and $F$. oxysporum f. sp. lycopersici were taken from the Fungal Genome Initiative (Haas et al. 2011). The reference F. solani (Sayers et al. 2012) sequence was obtained from NCBI/RefSeq. All other reference sequences were obtained from NCBI/GenBank. The $F$. solani sequence was used as an outgroup, in accordance with previous reconstructions of Fusarium phylogeny demonstrating early divergence of this species (Watanabe et al. 2011).

In the case of the FUM1 gene, the analysed region was coding (partial 2nd exon of the gene; ca. $920 \mathrm{bp}$ ) and corresponds to the linker region between ketoacyl synthase and acyltransferase domains, as well as ca. $73 \mathrm{~N}$-terminal amino acids of the acyl transferase domain (domain boundaries predicted based on NCBI/CDD matches-MarchlerBauer et al. 2011). For FUM8, a shorter region of ca. 620 bp was successfully amplified and sequenced. The region covered a stretch of sequence including both coding and noncoding regions (full 4th and partial 5th exons, as well as partial 3rd and full 4th intron sequences). Additional reference sequences were included, in order to verify the monophyly of $F$. proliferatum biosynthetic genes. These represented known fumonisin-producing strains: $F$. oxysporum FRC O-1890 (Proctor et al. 2008) and $F$. verticillioides FGSC 8961 (Proctor et al. 2006).

Preparation of plant tissue samples

Two fruit fractions, pineapple skin and pineapple juice, were prepared for each sample in order to determine the in planta mycotoxin content. The skin was freeze-dried, homogenized and subjected to the same extraction procedure as used for rice cultures (see below). In juice preparation, the ripe fruit flesh was frozen at $-80{ }^{\circ} \mathrm{C}$, thawed, blended and centrifuged at $11,000 \times g$ and $6{ }^{\circ} \mathrm{C}$ to recover clear juice, which, after filtering through Whatman no. 4 filter paper, was used for the mycotoxin extraction protocol.
Preparation of rice cultures

Rice cultures (in three repetitions) were prepared for individual Fusarium isolates (Kostecki et al. 1999; Moretti et al. 2008). Long-grain rice samples (50 g per flask) were left overnight at room temperature with the addition of $12.5 \mathrm{ml}$ of water and sterilized by autoclaving the next day. Rice samples were subsequently inoculated with $4 \mathrm{~cm}^{2}$ of 7-dayold mycelium on PDA medium. The average culture humidity was kept at around $30 \%$ and maintained for 14 days at $25^{\circ} \mathrm{C}$. Afterwards, cultures were dried at room temperature for $48 \mathrm{~h}$.

Mycotoxin quantification

Fumonisins $B_{1}, B_{2}$ and $B_{3}$

Sample extracts were prepared from the dry 2-week-old rice cultures and pineapple skin fractions. Five grammes of each sample were homogenized for $3 \mathrm{~min}$ in $10 \mathrm{ml}$ of methanolwater $(3: 1, \mathrm{v} / \mathrm{v})$ and filtered through Whatman no. 4 filter paper. The detailed procedure of extraction and purification of FB analogues was reported earlier (Waśkiewicz et al. 2010). Purified fumonisins content of methanol extracts and pineapple juice was measured using the highperformance liquid chromatography (HPLC) method (Waśkiewicz et al. 2010). A Waters 2695 apparatus (Waters Division of Millipore, Milford, MA, USA) with an XBridge column $(3.9 \times 100 \mathrm{~mm})$ and a Waters 2475 fluorescence detector $\left(\lambda_{\mathrm{Ex}}=335 \mathrm{~nm}\right.$ and $\left.\lambda_{\mathrm{Em}}=440 \mathrm{~nm}\right)$ were used. The detection limits were $10 \mathrm{ng} \mathrm{g}^{-1}$ for $\mathrm{FB}_{1}-\mathrm{FB}_{3}$. Preliminary, positive results (on the basis of retention time) were confirmed by thorough HPLC analysis and compared with the relevant calibration curves (the correlation coefficients for $\mathrm{FB}_{1}, \mathrm{FB}_{2}$ and $\mathrm{FB}_{3}$ were 0.9967, 0.9981 and 0.9966, respectively). Recoveries for $\mathrm{FB}_{1}, \mathrm{FB}_{2}$ and $\mathrm{FB}_{3}$ were 93, 97 and $87 \%$, respectively. Recovery coefficients were measured in triplicate by extracting the mycotoxins from blank samples spiked with $10-100 \mathrm{ng} \mathrm{g}^{-1}$ of the compound. The relative standard deviations for all fumonisins were less than $8 \%$.

\section{Beauvericin and moniliformin}

Samples $(15 \mathrm{~g})$ of rice cultures and pineapple skin were homogenized with $75 \mathrm{ml}$ of acetonitrile:methanol:water (16:3:1, v/v/v) and filtered (Whatman no. 4 filter paper). Pineapple juice samples were also filtered. The filtrate was defatted twice with $25 \mathrm{ml}$ of heptane. The bottom layer was evaporated to dryness and the resulting residue subsequently dissolved in $50 \mathrm{ml}$ of methanol:water $(55: 45, \mathrm{v} / \mathrm{v})$ and extracted twice with $25 \mathrm{ml}$ of dichloromethane. The aqueous, bottom phase (containing MON) was concentrated to 
$1 \mathrm{ml}$, while the $\mathrm{CH}_{2} \mathrm{Cl}_{2}$ phase (containing BEA) was evaporated to dryness and purified according to the method described by Kostecki et al. (1999).

BEA and MON were quantified using a Waters 2695 apparatus with a C18 Nova Pak column $(3.9 \times 150 \mathrm{~mm}$ for BEA and $3.9 \times 300 \mathrm{~mm}$ for MON) and a Waters 2996 Photodiode Array Detector (Waters, Milford, MA, USA) $\left(\lambda_{\max }=\right.$ $205 \mathrm{~nm}$ for BEA and $\lambda_{\max }=229 \mathrm{~nm}$ for MON). The HPLC conditions for BEA included a constant flow rate of $0.6 \mathrm{ml} \mathrm{min}{ }^{-1}$ and acetonitrile:water $(85: 15, \mathrm{v} / \mathrm{v})$ was used as the mobile phase. The detection limit for BEA was $10 \mathrm{ng} \mathrm{g}^{-1}$. Acetonitrile:water $(15: 85, \mathrm{v} / \mathrm{v})$ buffered with $10 \mathrm{ml} 0.1 \mathrm{M}$ $\mathrm{K}_{2} \mathrm{HPO}_{4}$ in $40 \% t$-butyl-ammonium hydroxide in $1 \mathrm{~L}$ of solvent was used as the mobile phase for MON analysis (flow rate $0.6 \mathrm{ml} \mathrm{min}^{-1}$ ), with the detection limit set at $25 \mathrm{ng} \mathrm{g}^{-1}$. Positive results (on the basis of retention time) were confirmed by HPLC analysis and comparison with the relevant calibration curve (the correlation coefficients for BEA and MON were 0.9970 and 0.9988 , respectively). Recoveries for BEA and MON were 91 and $94 \%$, respectively, which were measured in triplicate by extracting the mycotoxins from blank samples spiked with $10-100 \mathrm{ng} \mathrm{g}^{-1}$ of the compounds. The relative standard deviation values were less than $7 \%$ for BEA and less than $5 \%$ for MON.

\section{Results}

Strain isolation, molecular identification and phylogeny

Forty-four Fusarium strains were isolated and purified during this study. Some plant samples yielded more than one individual, but only single strains of a species were subjected to subsequent analyses. To assure that the strains are pure and unique, a single-spore subculturing was performed where possible using the procedure described by Leslie and Summerell (2006). This was not possible for all strains, as some of them did not develop spores under laboratory conditions (results not shown).

Partial sequences of the translation elongation factor gene $(t e f-1 \alpha)$ from the strains tested were compared to the reference sequences deposited in the NCBI GenBank using BLASTN. Ten Fusarium species were identified: $F$. ananatum, $F$. concentricum, $F$. fujikuroi, $F$. guttiforme, $F$. incarnatum, $F$. oxysporum, $F$. polyphialidicum, $F$. proliferatum, $F$. temperatum and $F$. verticillioides. $F$. proliferatum and $F$. ananatum were identified with the highest frequencies (15 and 14 isolates, respectively). Only single occurrences of F. fujikuroi, F. guttiforme, F. temperatum and $F$. verticillioides species were observed (Fig. 1 and Table 2). Most of the isolates originated from Costa Rica and Ecuador, with only a few samples being from Hawaii, Honduras, Indonesia and Vietnam. Phylogenetic relationships between the isolates were reconstructed (Fig. 1), including the reference sequences of model strains of $F$. graminearum, $F$. oxysporum, $F$. verticillioides and $F$. solani, as well as several other accessions of closely related species (see the Materials and Methods section).

The phylogeny reconstruction for the tef- $1 \alpha$ fragment supports clear, early divergence of $F$. polyphialidicum strains from the bulk of the considered species. The reconstructed phylogeny shows moderate support for two clades for the majority of all the analyzed $F$. proliferatum strains, except for KF 3408 (two clades with supports of 66 and $56 \%$, respectively).

Notably, F. guttiforme descent is unresolved in this phylogeny. Some $F$. guttiforme strains (KF 3327, NRRL 22945, ITEM 7611) appear to share common descent with $F$. ananatum (61\% bootstrap support), while grouping with F. begoniae NRRL 25300 is implied for two other strains (MRC 6782 and MRC 7539). This suggests the possible misidentification of KF 3327 and ITEM 6711 strains in their respective collections, as some of the model $F$. guttiforme strains (e.g. NRRL 22945) have been previously reidentified as $F$. ananatum in the paper describing this recently characterized species (Jacobs et al. 2010).

\section{Growth speed}

Thirty-one Fusarium isolates representing ten identified species were subjected to the analysis of growth speed at $25^{\circ} \mathrm{C}$. F. incarnatum and $F$. concentricum strains formed the colonies with the greatest speed and $F$. guttiforme and $F$. polyphialidicum were the species for which colony size increase was observed with the lowest rates. To maximize the clarity of the results obtained, only one isolate per species was included (Fig. 2), except for two isolates of $F$. ananatum, F. polyphialidicum and F. proliferatum, samples which delineate the limits of intra-specific differences observed for growth speeds.

Identification of mycotoxin biosynthetic genes

The presence of FUM1 and FUM8 genes (encoding the polyketide synthase and PLP-dependent aminotransferase from the fumonisin biosynthetic gene cluster, respectively) was confirmed in the $F$. fujikuroi, F. proliferatum, $F$. temperatum and $F$. verticillioides strains, though with minor exceptions, namely, the F. fujikuroi KF 3381 strain gave no amplification for FUM1 and a single strain of $F$. ananatum (KF 3316) amplified the FUM1 gene marker with low efficiency. The markers for trichothecene (TRI5 encoding the trichodiene synthase and TRII3 encoding the P450 monooxygenase determining deoxynivalenol and nivalenol chemotypes), as well as two zearalenone biosynthetic genes 


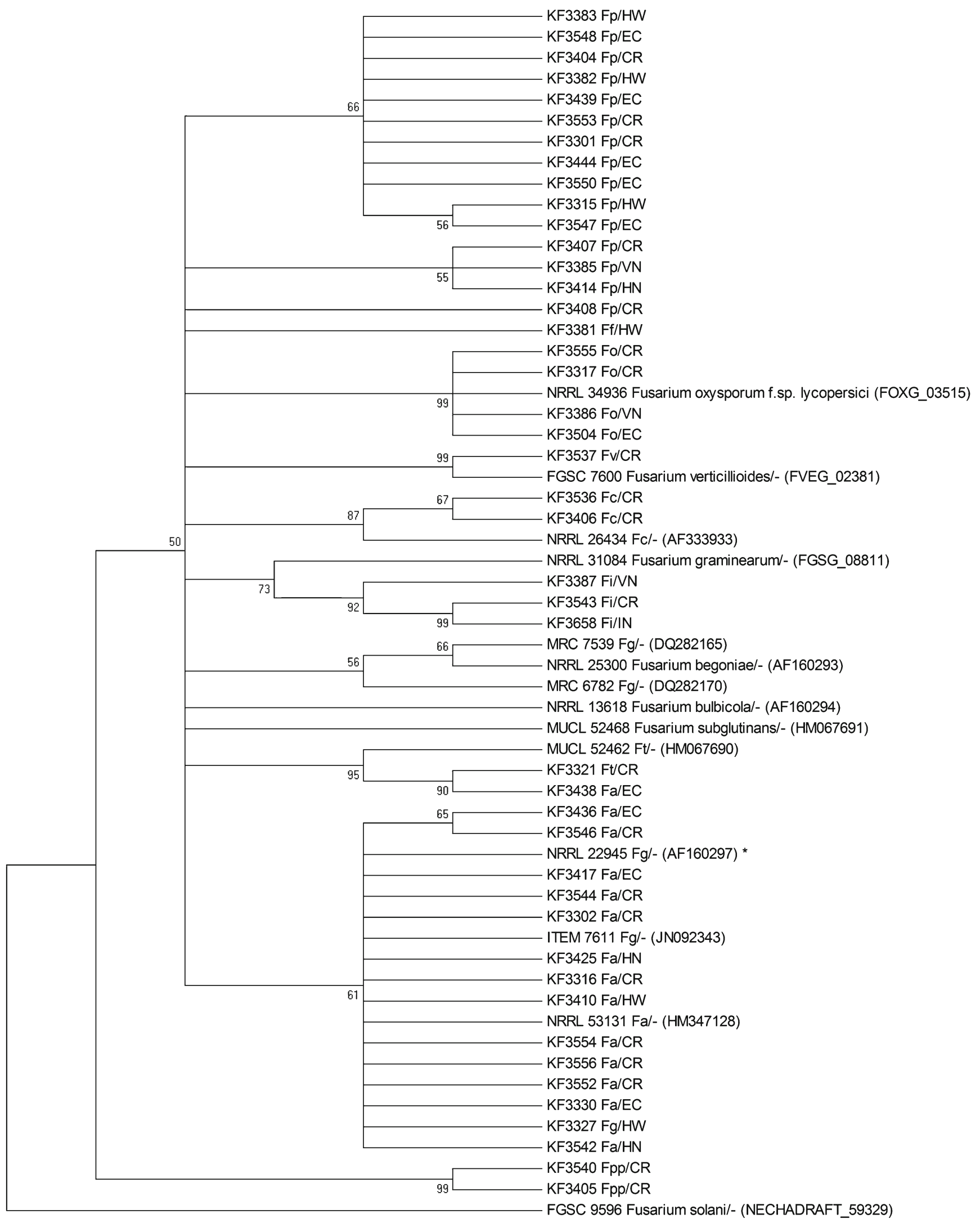


Fig. 1 The most parsimonious tree created on the basis of translation elongation factor $1 \alpha(t e f-1 \alpha)$ sequences of 44 isolates of ten Fusarium species, as well as 14 additional sequences from publicly available model strains. F. solani $(H$. haematococca MP VI) was used as an outgroup in the analysis. The consistency index for the first most parsimonious tree was 0.587 , and the retention index was 0.803 . A total of 277 positions were analysed (complete deletion of gapped positions from the initial alignment of 427 base pairs), of which 69 were parsimony informative. The tree was obtained using the maximum parsimony approach (closest neighbour interchange with search level 3 based on ten replicates for the initial tree construction) and tested by bootstrapping (1,000 replicates) with a cut-off value of $50 \%$. Abbreviations used for the species/country of origin: $F a F$. ananatum;, Ff F. fujikuroi; Fg F. guttiforme; Fi F. incarnatum; Fo F. oxysporum; Fpp F. polyphialidicum; Fp F. proliferatum; Ft F. temperatum; Fv $F$. verticillioides; $C R$ Costa Rica; EC Ecuador; $H A$ Hawaii; $H O$ Honduras; IN Indonesia; $V N$ Vietnam. For 12 model strains, either gene identifiers (from BROAD/JGI model sequences of $F$. graminearum, $F$. verticillioides, $F$. oxysporum, $F$. solani) or GenBank accession codes (all other cases) are given in parentheses. ${ }^{*} F$. guttiforme NRRL 22945 subsequently re-identified as $F$. ananatum by Jacobs et al. (2010); see also the discussion of the tef- $1 \alpha$ phylogeny in the Results section

(PKS4 and PKS13 encoding two polyketide synthases), were not found in any of the analysed samples (data not shown). A weak amplification of TRI13 fragment specific for nivalenol producers was observed in the case of DNA extracted from pineapple skin sample Ecu1_s. Sequencing of the fragment was confirmed to be the P450 monooxygenase from the TRI cluster of the $F$. graminearum variant (253 nucleotides with $99 \%$ identities). Although it was not possible to purify any F. graminearum isolate from this plant material, still, the skin sample contained trace amounts of nivalenol (19.13 $\mathrm{ng} \mathrm{g}^{-1}$ ), which suggests the presence of the pathogen. Using an esynl gene-specific marker, it was not possible to confirm the presence of the target gene. However, an additional pair of primers was used to amplify the sequence from BEA-producing species (Table 1). All isolates except for three $F$. incarnatum and one $F$. verticillioides had the gene present (Table 2). Partial sequences of FUM1 and FUM8 genes from all isolates with the genes present were examined to verify their origin and cross-reference the toxigenic capability with inferred species (assignments based on the tef- $1 \alpha$ sequence). The only exceptions were isolates $\mathrm{KF} 3316$ ( $F$. ananatum) and KF 3414 ( $F$. proliferatum), for which neither FUM1 nor FUM8 sequences could not be obtained, in spite of their successful amplification (Table 2). Phylogenetic trees were constructed, bootstrapped and topology visualized with not less than $50 \%$ of support (Figs. 3 and 4).

Notably, the divergence of $F$. proliferatum and $F$. verticillioides/F. oxysporum (Waalwijk et al. 2004) is well supported by both FUM1 and FUM8 phylogenies. The respective reconstructions also demonstrate close relationships between singular F. temperatum (FUMI and FUM8) and F. fujikuroi (FUM8) genes with the F. proliferatum genes (>90\% bootstrap support values for clades).

Mycotoxins synthesized in planta and in vitro

The mycotoxins of three groups, BEA, MON and fumonisins $B_{1}, B_{2}$ and $B_{3}$, were quantified in five samples of pineapple juice and skin fractions originating from Ecuador and Costa Rica. To investigate the mycotoxigenic abilities of individual isolates, the cultures of sterilized rice were used. Only a small group of isolates could not be tested; being highly susceptible to the storage conditions (nine isolates out of 44 studied), the mycelia were not viable after a few months of cold storage at $-20{ }^{\circ} \mathrm{C}$.

The inter-specific variability of mycotoxigenic abilities displayed by the set of isolates studied is presented in Table 3. To facilitate the comparison of in planta versus in vitro mycotoxin contents, isolates purified from analyzed pineapple fruit samples were separated from the others and appended in Table 4.

\section{Discussion}

Recent studies reported mainly F. guttiforme as the causative agent of pineapple fusariosis (Ploetz 2006). Nevertheless, Jacobs et al. (2010) demonstrated $F$. ananatum as the emerging species involved in pineapple fruit lesions in South Africa. In the present study, numerous Fusarium species were obtained from pineapple plant samples besides the two above-mentioned species, namely, F. concentricum, $F$. fujikuroi, F. incarnatum, F. oxysporum, F. polyphialidicum, $F$. proliferatum, F. temperatum and $F$. verticillioides. In several cases, two different species were identified in the same plant sample (Table 4). The majority of the species occurred with low frequencies (see Table 2) and have not been reported as pineapple pathogens, thus, inoculation experiments are needed in order to confirm the ability of those strains to infect and colonize the pineapple tissue. Taking into account that the harvested pineapple fruit is usually protected from pathogen infiltration and also from colonization by saprophytic agents by spraying a fungicide (like Bayleton), this finding could be helpful in corroborating the supposition that the identified Fusaria are not necessarily exogenous contaminants introduced during transport and storage.

The high incidence of $F$. proliferatum deserves significant attention. Recently, Stępień et al. (2011b) characterized the genetic diversity of several strains obtained from pineapple in respect to genotypes obtained from different hosts, showing significant intra-specific diversity in relation to the host of origin. Pineapple-derived strains grouped firmly together, apart from garlic, maize, rice and asparagus strains (Stępień et al. 2011b). The co-occurrence of multiple 
Table 2 Forty-four isolates of ten Fusarium species purified from contaminated pineapples, their origin, year of isolation and the presence of FUM1 and FUM8 genes from the fumonisin biosynthetic pathway and bsyn 1 from the beauvericin (BEA) biosynthetic pathway
${ }^{a}$ Strains for which single spore subcultures were not performed

\begin{tabular}{|c|c|c|c|c|c|c|}
\hline Isolate & Species & Year & Origin & FUM1 & FUM8 & bsynl \\
\hline KF $3302^{a}$ & F. ananatum & 2008 & Costa Rica & - & - & + \\
\hline $\mathrm{KF} 3316^{\mathrm{a}}$ & F. ananatum & 2008 & Costa Rica & + (weak) & - & + \\
\hline KF 3330 & F. ananatum & 2008 & Ecuador & - & - & + \\
\hline KF 3410 & F. ananatum & 2009 & Hawaii & - & - & + \\
\hline KF 3417 & F. ananatum & 2010 & Ecuador & - & - & + \\
\hline KF 3425 & F. ananatum & 2009 & Honduras & - & - & + \\
\hline KF 3436 & F. ananatum & 2010 & Ecuador & - & - & + \\
\hline KF 3438 & F. ananatum & 2010 & Ecuador & - & - & + \\
\hline KF 3542 & F. ananatum & 2010 & Honduras & - & - & + \\
\hline KF 3544 & F. ananatum & 2009 & Costa Rica & - & - & + \\
\hline KF 3546 & F. ananatum & 2011 & Costa Rica & - & - & + \\
\hline KF 3552 & F. ananatum & 2011 & Costa Rica & - & - & + \\
\hline KF 3554 & F. ananatum & 2011 & Costa Rica & - & - & + \\
\hline KF 3556 & F. ananatum & 2011 & Costa Rica & - & - & + \\
\hline KF 3406 & F. concentricum & 2009 & Costa Rica & - & - & + \\
\hline KF 3536 & F. concentricum & 2010 & Costa Rica & - & - & + \\
\hline KF 3381 & F. fujikuroi & 2009 & Hawaii & - & + & + \\
\hline KF 3327 & F. guttiforme & 2008 & Hawaii & - & - & + \\
\hline $\mathrm{KF} 3387^{\mathrm{a}}$ & F. incarnatum & 2009 & Vietnam & - & - & - \\
\hline $\mathrm{KF} 3543^{\mathrm{a}}$ & F. incarnatum & 2009 & Costa Rica & - & - & - \\
\hline KF $3658^{\mathrm{a}}$ & F. incarnatum & 2011 & Indonesia & - & - & - \\
\hline KF 3317 & F. oxysporum & 2008 & Costa Rica & - & - & + \\
\hline KF 3386 & F. oxysporum & 2009 & Vietnam & - & - & + \\
\hline KF 3504 & F. oxysporum & 2010 & Ecuador & - & - & + \\
\hline KF 3555 & F. oxysporum & 2011 & Costa Rica & - & - & + \\
\hline $\mathrm{KF} 3405^{\mathrm{a}}$ & F. polyphialidicum & 2009 & Costa Rica & - & - & + \\
\hline $\mathrm{KF} 3540^{\mathrm{a}}$ & F. polyphialidicum & 2010 & Costa Rica & - & - & + \\
\hline KF 3301 & F. proliferatum & 2008 & Costa Rica & + & + & + \\
\hline KF 3315 & F. proliferatum & 2008 & Hawaii & + & + & + \\
\hline KF 3382 & F. proliferatum & 2009 & Hawaii & + & + & + \\
\hline KF 3383 & F. proliferatum & 2009 & Hawaii & + & + & + \\
\hline KF 3385 & F. proliferatum & 2009 & Vietnam & + & + & + \\
\hline KF 3404 & F. proliferatum & 2009 & Costa Rica & + & + & + \\
\hline KF 3407 & F. proliferatum & 2009 & Costa Rica & + & + & + \\
\hline KF 3408 & F. proliferatum & 2009 & Costa Rica & + & + & + \\
\hline KF 3414 & F. proliferatum & 2010 & Honduras & + & + & + \\
\hline KF 3439 & F. proliferatum & 2010 & Ecuador & + & + & + \\
\hline KF 3444 & F. proliferatum & 2010 & Ecuador & + & + & + \\
\hline KF 3547 & F. proliferatum & 2011 & Ecuador & + & + & + \\
\hline KF 3548 & F. proliferatum & 2011 & Ecuador & + & + & + \\
\hline KF 3550 & F. proliferatum & 2011 & Ecuador & + & + & + \\
\hline KF 3553 & F. proliferatum & 2011 & Costa Rica & + & + & + \\
\hline KF 3321 & F. temperatum & 2008 & Costa Rica & + & + & + \\
\hline KF 3537 & F. verticillioides & 2010 & Costa Rica & + & + & - \\
\hline
\end{tabular}

Fusarium genotypes in a single plant sample can often result in a contaminated culture. However, the purification procedure and the acquisition of the tef-1 $\alpha$ sequence from all the
Fusarium strains studied serves as a strong, though still indirect, proof of culture purity. The phylogenetic analysis of our isolate set revealed a high similarity level among the 
collection of 14 obtained $F$. ananatum isolates, as well as their close relationship with $F$. guttiforme. The latter finding supports well the results presented by Jacobs et al. (2010). Moreover, several other species appeared as being closely related to $F$. ananatum and $F$. guttiforme: $F$. begoniae, $F$. bulbicola, F. succisae, F. subglutinans and F. temperatum, the last of which was described recently by Scauflaire et al. (2011). The population of 16 isolates belonging to $F$. proliferatum appeared as being closely related to F. fujikuroi (Fig. 1). No correlation was observed between the country of origin and the species distribution.

After 4 days of isolate cultivation, the colonies measured from 20 to $51 \mathrm{~mm}$ and after 7 days from 40 to $80 \mathrm{~mm}$ (Fig. 2). The fastest-growing species appeared to be $F$. concentricum and $F$. incarnatum. On the other hand, the slowest-growing strains were isolates of $F$. guttiforme and $F$. polyphialidicum. Considerable intraspecific variance was found in other species, particularly in the cases of $F$. ananatum and $F$. proliferatum, where the differences in the colony diameter between the fastest- and the slowest-growing isolates after 7 days of culturing reached $15 \mathrm{~mm}$ (Fig. 2). Thus, the speed of growth could not be used as a species discriminatory factor. What is more likely, the studied species differ in mycotoxigenic potential, and this particular question was chosen as the subject for further research. Several gene-specific PCR assays have been performed to identify the essential genes of the respective metabolic pathways in order to validate the ability of the examined isolates to synthesise other groups of mycotoxins. These included TRI5 and TRI13 genes from the trichothecene biosynthetic cluster, PKS4 and PKS13 genes from the zearalenone cluster and esynl-encoding enniatin synthase. None of the genotypes tested had the marker fragments present. However, an F. graminearum TRII3 gene fragment specific for nivalenol producers was amplified using a DNA template extracted from the pineapple skin sample Ecu1_s. Although it was not possible to purify any $F$. graminearum isolate from this plant material, the tested sample contained $19.13 \mathrm{ng} \mathrm{g}^{-1}$ of nivalenol. This particular finding suggests that the approach utilizing PCR-based identification of specific biosynthetic genes to predict the presence of mycotoxins is very sensitive, even for such complex matrices as uncultured strains present in the plant material. Concerning cyclic peptide biosynthesis, it was already proven that enniatins and BEA share a common metabolic pathway (Nicholson et al. 2004), and, besides enniatins, the esyn 1 gene is also involved in BEA biosynthesis. Previous studies have already shown the sequence divergence between enniatin versus BEAproducing strains (Stępień and Waśkiewicz 2013). Therefore, an additional primer pair was used to amplify a portion of the esynl homologue from BEA-producing species (Table 1) and the gene was identified in 40 out of 44 isolates studied, suggesting the ability of those strains to synthesize BEA (Table 2). All isolates of $F$. proliferatum, $F$. fujikuroi, $F$. verticillioides and $F$. temperatum had both FUM1 and FUM8 genes successfully verified by amplification, except for FUM1 in $F$. fujikuroi (KF 3381) and a single isolate of $F$. proliferatum (KF 3414), for which the sequence could not be read. The outliers can be explained by the interspecific sequence divergence and are consistent with the
Fig. 2 Colony diameter of the 13 chosen strains of ten Fusarium species measured in 24-h intervals on potato dextrose agar (PDA) medium at $25{ }^{\circ} \mathrm{C}$. Two strains of $F$. ananatum (KF 3410 and 3425), F. polyphialidicum (KF 3405 and 3540) and F. proliferatum (KF 3382 and 3314) were included to show the intraspecific variance.

Abbreviations used for the species/country of origin: $\mathrm{FaF}$. ananatum; Fc F. concentricum; Ff F. fujikuroi; Fg F. guttiforme; Fi F. incarnatum; Fo F. oxysporum; Fpp F. polyphialidicum; $F p F$. proliferatum; Ft F. temperatum; $F v F$. verticillioides; $C O$ Costa Rica; $H A$ Hawaii; $H O$

Honduras; IN Indonesia; $V N$ Vietnam

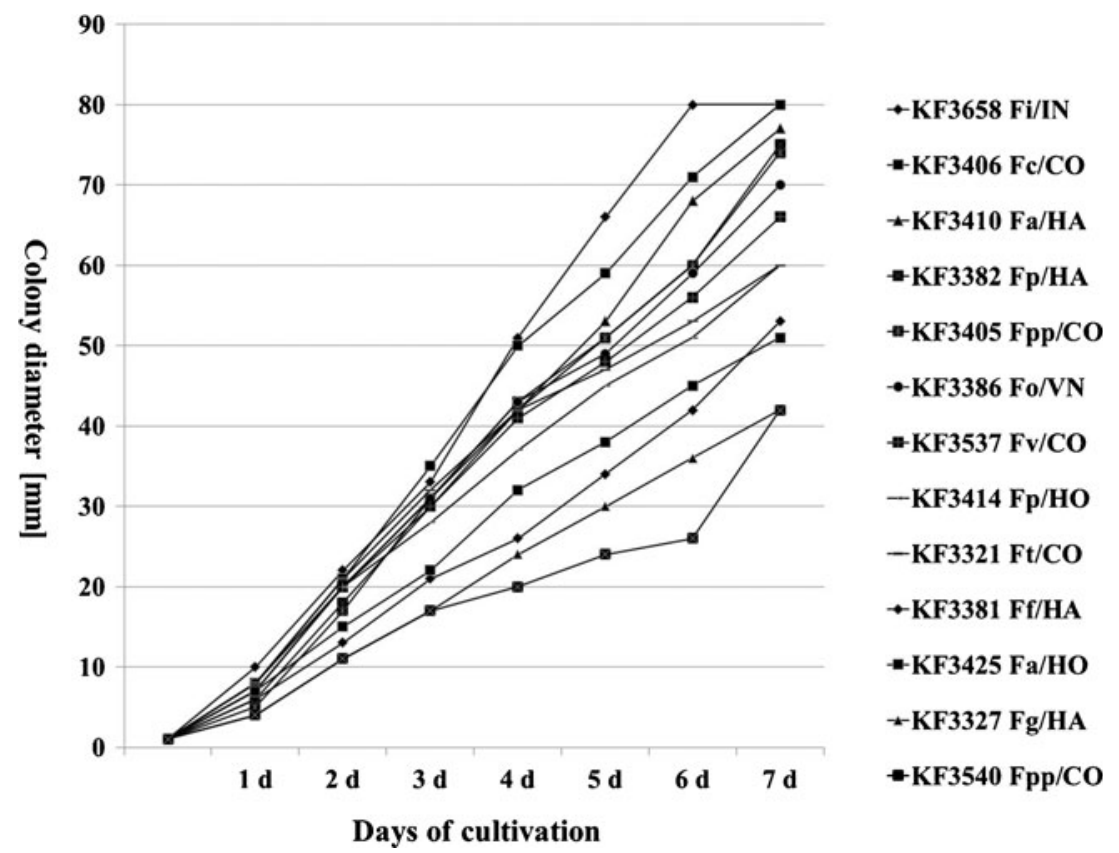




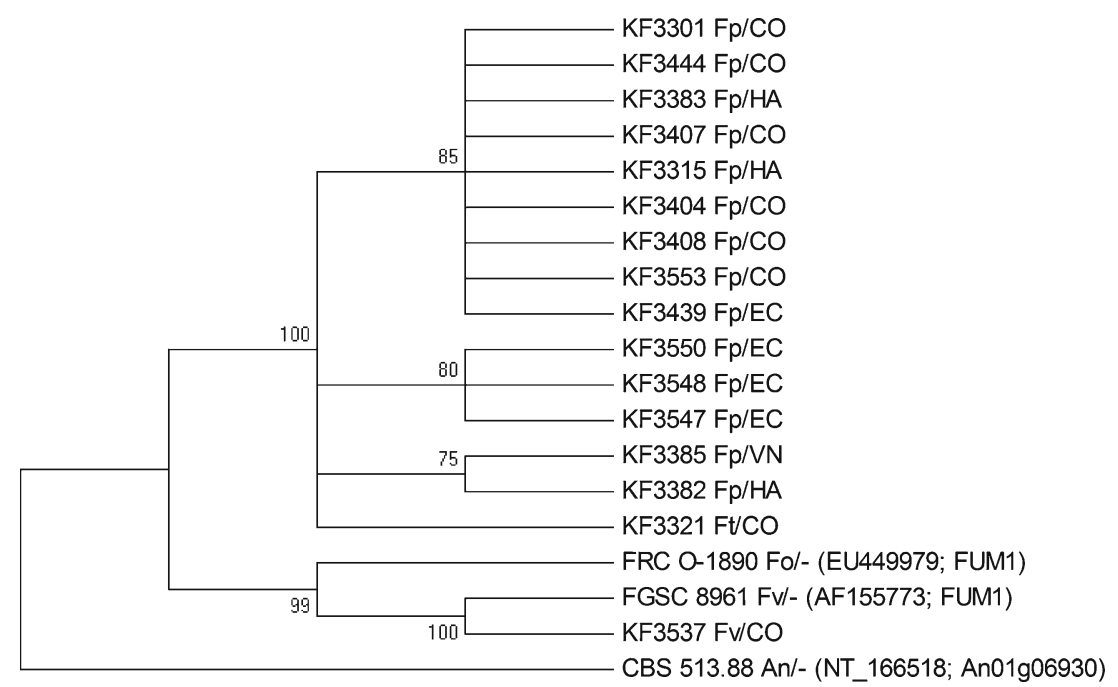

Fig. 3 Consensus phylogenetic tree obtained based on the partial FUM1 gene sequences of $F$. proliferatum, $F$. temperatum and $F$. verticillioides isolates used in the study (16 isolates). The FUM1 homologue from Aspergillus niger CBS 513.88 was used as an outgroup. Additional sequences from FGSC 8961 (F. verticillioides) and FRC O-1890 (F. oxysporum) were also included in the analysis. The tree was obtained using the maximum parsimony approach (CNI level 3, with ten replicates for the initial tree construction) and tested by bootstrapping $(1,000$

previous work, where, using a different pair of primers, it was possible to identify the FUM1 gene (Stępień et al. 2011b). In both the FUM1 and FUM8 phylogenies, reference sequences of homologues from Aspergillus replicates) with a cut-off value of $50 \%$. The consistency index for the first most parsimonious tree was 0.896 and the retention index was 0.923 . A total of 555 positions were analysed, of which 116 were parsimony informative. Abbreviations used for the species/country of origin: $A n$ Aspergillus niger; Fp F. proliferatum; Ft F. temperatum; Fv F. verticillioides; $C O$ Costa Rica; EC Ecuador; HA Hawaii; HO Honduras; $I N$ Indonesia; $V N$ Vietnam. For GenBank reference sequences, both the accession number and locus tag are quoted in parentheses

niger strain CBS 513.88 (Pel et al. 2007) were used as outgroups. The details of the exact evolutionary scenario leading to the emergence of the functional fumonisin cluster in both A. niger and Fusarium sp. are still unresolved, namely,

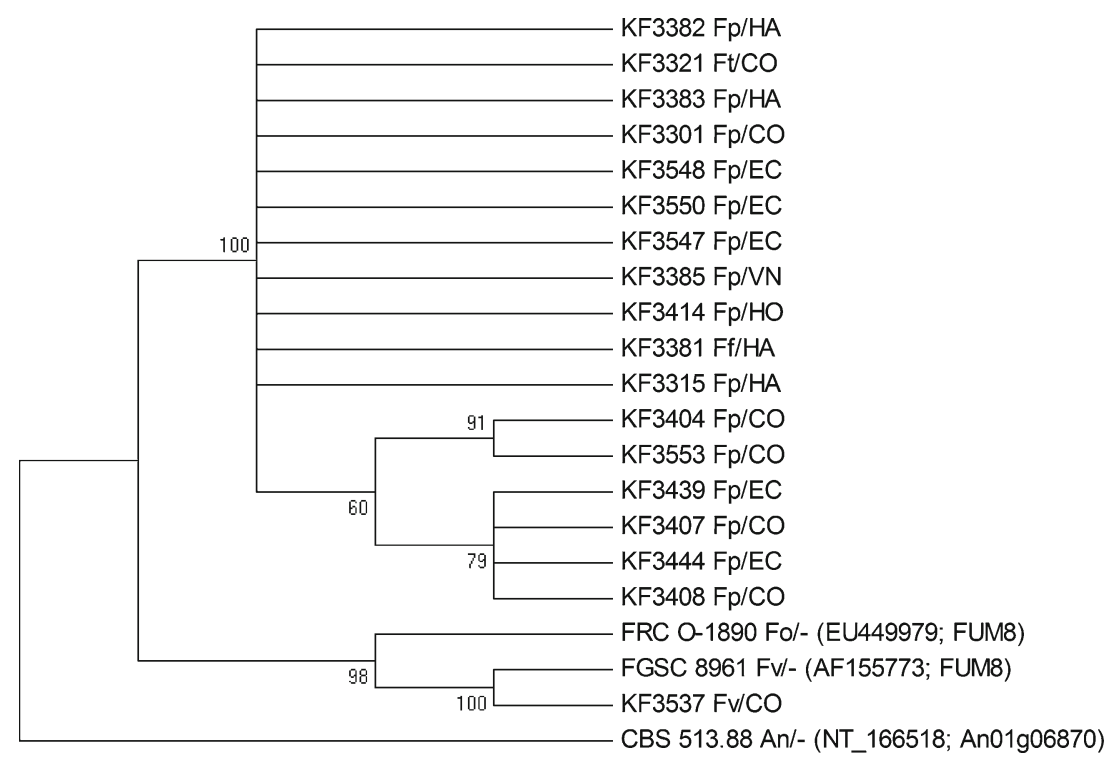

Fig. 4 Consensus phylogenetic tree obtained based on the partial FUM8 gene sequence of $F$. proliferatum, $F$. temperatum and $F$. verticillioides strains used in the study (18 isolates). The FUM8 homologue from Aspergillus niger CBS 513.88 was used as an outgroup. Additional sequences from FGSC 8961 (F. verticillioides) and FRC O-1890 (F. oxysporum) were also included in the analysis. The consistency index for the first most parsimonious tree was 0.858 and the retention index was 0.894 . The tree was obtained using the maximum parsimony approach
(CNI level 3, with ten replicates for the initial tree construction) and tested by bootstrapping (1,000 replicates) with a cut-off value of $50 \%$. A total of 526 positions was analysed, of which 105 were parsimony informative. Abbreviations used for the species/country of origin: An Aspergillus niger; Ff F. fujikuroi; Fp F. proliferatum; Ft F. temperatum; Fv F. verticillioides; $C O$ Costa Rica; EC Ecuador; HA Hawaii; HO Honduras; $I N$ Indonesia; $V N$ Vietnam. For GenBank reference sequences, both the accession number and locus tag are quoted in parentheses 
Table 3 Means and standard deviations (SDs) of the amounts of fumonisins ( $\mathrm{FB}_{1}-\mathrm{FB}_{3}$ ), moniliformin (MON) and beauvericin (BEA) concentrations produced in vitro by 28 isolates of nine Fusarium species

\begin{tabular}{|c|c|c|c|c|c|c|}
\hline Isolate & Fusarium species & $\begin{array}{l}\mathrm{FB}_{1} \\
(\mu \mathrm{g} / \mathrm{g})\end{array}$ & $\begin{array}{l}\mathrm{FB}_{2} \\
(\mu \mathrm{g} / \mathrm{g})\end{array}$ & $\begin{array}{l}\mathrm{FB}_{3} \\
(\mu \mathrm{g} / \mathrm{g})\end{array}$ & $\begin{array}{l}\text { MON } \\
(\mu \mathrm{g} / \mathrm{g})\end{array}$ & $\begin{array}{l}\text { BEA } \\
(\mu \mathrm{g} / \mathrm{g})\end{array}$ \\
\hline KF 3302 & F. ananatum & $0.16 \pm 0.05$ & $0.09 \pm 0.02$ & $0.04 \pm 0.01$ & ND 0 & $0.42 \pm 0.09$ \\
\hline KF 3330 & F. ananatum & $9.80 \pm 2.21$ & $1.02 \pm 0.53$ & $0.32 \pm 0.02$ & $0.04 \pm 0.01$ & $0.96 \pm 0.07$ \\
\hline KF 3410 & F. ananatum & nt & $\mathrm{nt}$ & nt & ND & $0.70 \pm 0.03$ \\
\hline KF 3417 & F. ananatum & $\mathrm{nt}$ & $\mathrm{nt}$ & $\mathrm{nt}$ & ND & $4.70 \pm 0.56$ \\
\hline KF 3425 & F. ananatum & nt & $\mathrm{nt}$ & nt- & ND & $5.85 \pm 0.87$ \\
\hline KF 3438 & F. ananatum & $\mathrm{nt}$ & $\mathrm{nt}$ & nt & ND & ND \\
\hline KF 3436 & F. ananatum & $3.29 \pm 0.45$ & $0.95 \pm 0.05$ & $0.32 \pm 0.02$ & ND & $91.47 \pm 11.12$ \\
\hline KF 3406 & F. concentricum & $10.41 \pm 2.11$ & ND & $0.28 \pm 0.04$ & $30.04 \pm 4.12$ & $0.51 \pm 0.06$ \\
\hline KF 3536 & F. concentricum & $9.38 \pm 0.97$ & ND & $0.28 \pm 0.03$ & ND & ND \\
\hline KF 3381 & F. fujikuroi & $1,558.98 \pm 187.15$ & $465.96 \pm 39.76$ & $81.64 \pm 9.76$ & $27.55 \pm 3.54$ & $1.65 \pm 0.28$ \\
\hline KF 3327 & F. guttiforme & $\mathrm{nt}$ & $\mathrm{nt}$ & nt & ND & $7.70 \pm 1.15$ \\
\hline KF 3386 & F. oxysporum & ND & ND & ND & $17.23 \pm 2.27$ & ND \\
\hline KF 3504 & F. oxysporum & ND & ND & ND & $2.22 \pm 0.18$ & $3.93 \pm 0.55$ \\
\hline KF 3405 & F. polyphialidicum & $2.91 \pm 0.28$ & $0.41 \pm 0.03$ & $0.11 \pm 0.02$ & ND & $6.49 \pm 1.09$ \\
\hline KF 3540 & F. polyphialidicum & $18.87 \pm 3.42$ & $4.30 \pm 0.37$ & $1.15 \pm 0.23$ & $0.02 \pm 0.01$ & $6.78 \pm 0.75$ \\
\hline $\operatorname{KF} 3301^{\mathrm{a}}$ & F. proliferatum & $1,353.00 \pm 154.90$ & $496.00 \pm 39.65$ & $133.00 \pm 21.98$ & $110.56 \pm 9.76$ & $0.83 \pm 0.06$ \\
\hline $\mathrm{KF} 3315^{\mathrm{a}}$ & F. proliferatum & $1,820.00 \pm 202.11$ & $534.00 \pm 21.70$ & $113.00 \pm 20.54$ & $59.40 \pm 4.44$ & $0.09 \pm 0.02$ \\
\hline KF 3382 & F. proliferatum & $1,785.76 \pm 176.53$ & $450.54 \pm 51.33$ & $132.90 \pm 18.77$ & $18.40 \pm 2.09$ & $3.39 \pm 0.28$ \\
\hline $\operatorname{KF} 3383^{\mathrm{a}}$ & F. proliferatum & $930.00 \pm 88.69$ & $204.00 \pm 017.73$ & $79.00 \pm 6.55$ & $158.46 \pm 11.63$ & $1.08 \pm 0.18$ \\
\hline KF $3385^{\mathrm{a}}$ & F. proliferatum & $7.01 \pm 0.64$ & $2.16 \pm 0.18$ & $0.79 \pm 0.04$ & $14.22 \pm 1.08$ & $2.26 \pm 0.65$ \\
\hline KF 3404 & F. proliferatum & $856.39 \pm 78.15$ & $330.03 \pm 20.18$ & $109.07 \pm 9.23$ & $49.31 \pm 3.32$ & $3.99 \pm 0.57$ \\
\hline KF 3407 & F. proliferatum & $2,419.32 \pm 199.53$ & $379.86 \pm 43.09$ & $139.77 \pm 10.44$ & $81.73 \pm 7.65$ & $4.15 \pm 0.22$ \\
\hline KF 3408 & F. proliferatum & $2,686.23 \pm 303.41$ & $757.94 \pm 54.31$ & $367.82 \pm 40.12$ & $27.68 \pm 1.72$ & $0.35 \pm 0.02$ \\
\hline KF 3414 & F. proliferatum & $3,299.01 \pm 276.80$ & $855.64 \pm 68.98$ & $593.08 \pm 49.52$ & $15.98 \pm 0.98$ & $41.13 \pm 3.74$ \\
\hline KF 3439 & F. proliferatum & $1,032.76 \pm 97.45$ & $134.60 \pm 10.25$ & $96.49 \pm 10.01$ & $93.08 \pm 10.13$ & $8.61 \pm 1.43$ \\
\hline KF 3444 & F. proliferatum & $1,568.18 \pm 209.83$ & $210.93 \pm 15.37$ & $140.35 \pm 9.12$ & $65.01 \pm 5.43$ & $24.75 \pm 3.11$ \\
\hline KF 3321 & F. temperatum & $2.25 \pm 0.32$ & $0.35 \pm 0.04$ & $0.08 \pm 0.02$ & $7.45 \pm 0.61$ & $12.48 \pm 0.89$ \\
\hline KF 3537 & F. verticillioides & $59.65 \pm 6.16$ & $19.37 \pm 0.99$ & $5.86 \pm 0.76$ & $0.07 \pm 0.01$ & $0.05 \pm 0.01$ \\
\hline
\end{tabular}

$N D$ not detected; $n t$ not tested

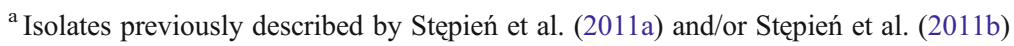

the direction of the ancestral horizontal transfer (Khaldi and Wolfe 2011) and dating cluster formation in light of different organization within $F$. verticillioides and $F$. proliferatum (Waalwijk et al. 2004). However, the outgroup choice itself is corroborated by both strong sequence divergence (ca. 55$60 \%$ protein sequence identity between $A$. niger and Fusarium genes) and previously mentioned analysis by Khaldi and Wolfe (2011).

To validate the potential risk of pineapple contamination with mycotoxins, BEA, MON and fumonisins contents were measured in fruit tissue samples (Table 4). Also, rice cultures of individual isolates were prepared in order to establish the mycotoxigenic potential of individual genotypes in controlled laboratory conditions (Table 3). Across all the analyzed isolates, F. proliferatum appeared to be the species producing the highest amounts of fumonisins (FBs) and
MON. Concerning FBs, only one isolate could be qualified as a low-efficiency producer (KF 3385) and only another two yielded less than $1 \mathrm{mg} \mathrm{g}^{-1}$ of $\mathrm{FB}_{1}$ and the most efficient producer (KF 3414) yielded about $3.3 \mathrm{mg} \mathrm{g}^{-1}$ of $\mathrm{FB}_{1}$. The $F$. fujikuroi $\mathrm{KF} 3381$ produced $\mathrm{FB}_{1}$ in a comparable amount of over $1.5 \mathrm{mg} \mathrm{g}^{-1}$ (Table 3). Both F. temperatum and $F$. verticillioides are known to produce $\mathrm{FBs}$ in significant amounts (Proctor et al. 1999; Scauflaire et al. 2011) and can be described as medium-efficiency producers (between 50 and $100 \mu \mathrm{g} \mathrm{g}^{-1}$ of $\mathrm{FB}_{1}$ produced) and the remaining species as low-efficiency producers. MON was also produced in the highest amounts by $F$. proliferatum isolates, though, in this case, the yield was not very high, with the highest value of $158 \mu \mathrm{g} \mathrm{g}^{-1}$. F. ananatum isolates did not produce MON, but KF 3436 synthesized BEA in the highest amount $\left(91 \mu \mathrm{g} \mathrm{g}^{-1}\right)$ of all the isolates tested (Table 3 ). 
Table 4 Means and standard deviations (SD) of the amounts of fumonisins $\left(\mathrm{FB}_{1}-\mathrm{FB}_{3}\right)$, moniliformin ( $\mathrm{MON}$ ) and beauvericin (BEA) concentrations measured in five samples of pineapple juice and skin fractions originating from Costa Rica (Cos) and Ecuador (Ecu), together with the mycotoxin yield for seven isolates of three Fusarium species purified from the respective samples

\begin{tabular}{|c|c|c|c|c|c|}
\hline Sample ID/Isolate No. & $\mathrm{FB}_{1}$ & $\mathrm{FB}_{2}$ & $\mathrm{FB}_{3}$ & MON & BEA \\
\hline \multicolumn{6}{|l|}{ Pineapple juice samples $(\mu \mathrm{g} / \mathrm{ml})$} \\
\hline $\operatorname{Cos} 1 \_j$ & $8.18 \pm 1.07$ & $0.94 \pm 0.09$ & $0.17 \pm 0.02$ & $0.20 \pm 0.01$ & 0.00 \\
\hline $\operatorname{Cos} 2 \mathrm{j}$ & $14.85 \pm 5.12$ & $1.46 \pm 0.32$ & $0.23 \pm 0.03$ & $0.04 \pm 0.01$ & 0.00 \\
\hline $\operatorname{Cos} 3 \_j$ & $21.01 \pm 4.89$ & $0.74 \pm 0.08$ & $0.17 \pm 0.03$ & $0.04 \pm 0.02$ & 0.00 \\
\hline $\operatorname{Cos} 4 \_j$ & $23.73 \pm 5.22$ & $1.21 \pm 0.24$ & $0.18 \pm 0.03$ & $0.03 \pm 0.01$ & 0.00 \\
\hline Ecu1_j & $22.18 \pm 3.38$ & $0.95 \pm 0.07$ & $0.23 \pm 0.04$ & $0.01 \pm 0.01$ & 0.00 \\
\hline \multicolumn{6}{|l|}{ Pineapple skin samples $(\mu \mathrm{g} / \mathrm{g})$} \\
\hline Cos1_s & $128.57 \pm 11.09$ & $1.27 \pm 0.09$ & $0.70 \pm 0.05$ & $0.79 \pm 0.06$ & $0.31 \pm 0.02$ \\
\hline $\operatorname{Cos} 2 \_s$ & $33.23 \pm 2.65$ & $0.64 \pm 0.05$ & $0.48 \pm 0.03$ & $0.02 \pm 0.01$ & $0.23 \pm 0.02$ \\
\hline Cos3_s & $33.06 \pm 2.88$ & $0.82 \pm 0.05$ & $0.74 \pm 0.05$ & $0.04 \pm 0.02$ & $0.36 \pm 0.01$ \\
\hline Cos4_s & $25.65 \pm 1.83$ & $0.59 \pm 0.06$ & $0.56 \pm 0.04$ & $0.06 \pm 0.02$ & $1.60 \pm 0.09$ \\
\hline Ecu1_s & $247.74 \pm 20.76$ & $1.48 \pm 0.11$ & $0.11 \pm 0.02$ & $0.08 \pm 0.03$ & $0.79 \pm 0.05$ \\
\hline \multicolumn{6}{|l|}{$\begin{array}{l}\text { Rice cultures of isolates obtained } \\
\text { from analyzed material }(\mu \mathrm{g} / \mathrm{g})\end{array}$} \\
\hline $\mathrm{KF} 3546(F$. ananatum/Cos 1$)$ & $3.62 \pm 0.27$ & $0.45 \pm 0.05$ & $0.11 \pm 0.01$ & $0.06 \pm 0.02$ & $2.46 \pm 0.34$ \\
\hline KF 3552 (F. ananatum/Cos2) & $10.32 \pm 0.87$ & $0.45 \pm 0.04$ & $0.39 \pm 0.05$ & $0.01 \pm 0.01$ & $3.49 \pm 0.37$ \\
\hline KF 3553 (F. proliferatum/Cos 3$)$ & $2,125.42 \pm 154.78$ & $368.79 \pm 54.41$ & $189.48 \pm 35.09$ & $23.90 \pm 6.18$ & $10.54 \pm 2.35$ \\
\hline KF 3554 (F. ananatum/Cos3) & $26.05 \pm 1.34$ & $5.09 \pm 0.72$ & $1.13 \pm 0.15$ & $0.03 \pm 0.01$ & $1.31 \pm 0.11$ \\
\hline KF 3555 (F. oxysporum/Cos4) & $10.97 \pm 0.99$ & $6.27 \pm 0.55$ & $0.47 \pm 0.05$ & $5.22 \pm 0.44$ & $3.24 \pm 0.45$ \\
\hline KF $3556(F$. ananatum/Cos4) & $3.73 \pm 0.41$ & $1.08 \pm 0.23$ & $0.47 \pm 0.06$ & $0.04 \pm 0.01$ & $1.73 \pm 0.15$ \\
\hline KF $3548($ F. proliferatum/Ecu1) & $1,861.16 \pm 115.76$ & $481.92 \pm 34.80$ & $98.40 \pm 10.11$ & $97.44 \pm 9.98$ & $53.88 \pm 7.68$ \\
\hline
\end{tabular}

Again, F. proliferatum isolates recovered from the analysed plant samples were the most effective FBs, MON and BEA producers. Interestingly, in the original pineapple samples Cos 2 and Cos4-samples that did not contain $F$. proliferatum but only $F$. ananatum and $F$. oxysporum-more FBs have been identified in planta than in the respective isolates cultured on rice. Such inconsistency might be explained at least two-fold:

(i) An additional unknown FBs producer was present in the infected fruit, but was not identified in cultures, or

(ii) Rice culture used for FBs biosynthesis in vitro was not a suitable medium for those strains causing low biosynthesis level.

In conclusion, concerning a contribution of individual species to the contamination of pineapple with mycotoxins, the role of $F$. ananatum, $F$. oxysporum, $F$. guttiforme and $F$. polyphialidicum as mycotoxin producers can be regarded as limited, while $F$. proliferatum emerges as a major, understated threat. The same conclusion can be drawn from the analysis of in planta mycotoxin content results. Pineapple skin from infected fruit contained as much as $250 \mu \mathrm{g} \mathrm{g}^{-1}$ of $\mathrm{FB}_{1}$ and the metabolite concentration in pineapple juice was about ten times lower. High FB content in the skin samples is likely caused by the concentration of toxins achieved by the application of a freeze-drying step. In both fractions, BEA and MON were of minor significance (Table 4). According to the US Food and Drug Administration (FDA) exposure guidelines, the total fumonisin content in corn-based food products may reach $2-4 \mathrm{ppm}$. This means that the naturally occurring FB levels in (stored) pineapple fruits are potentially hazardous to human health.

Taken as a whole, the obtained results demonstrate that, of all the species identified, $F$. ananatum and $F$. proliferatum are probably the most commonly occurring Fusaria and regarding mycotoxin produced, $F$. proliferatum can be potentially the most dangerous species found in plant tissues of pineapple. Additionally, they serve as a proof of the species' metabolic activity in planta and suggest the need for FBs contamination control in pineapple and, likely, in other tropical crops most often consumed in unprocessed form.

Acknowledgements This research was partially supported by the National Centre of Science (NCN) project NN 310 732440. Grzegorz Koczyk has been supported by the National Centre for Research and Development (NCBiR) grant LIDER 19/113/L-1/09/NCBiR/2010 ("Modelling, prediction and verification of toxigenic potential in fungi").

Open Access This article is distributed under the terms of the Creative Commons Attribution License which permits any use, distribution, and reproduction in any medium, provided the original author(s) and the source are credited. 


\section{References}

Błaszczyk L, Goyeau H, Huang XQ, Röder M, Stępień Ł, Chełkowski $\mathrm{J}$ (2004) Identifying leaf rust resistance genes and mapping gene Lr37 on the microsatellite map of wheat. Cell Mol Biol Lett 9:869-878

Boutigny A-L, Ward TJ, Van Coller GJ, Flett B, Lamprecht SC, O'Donnell K, Viljoen A (2011) Analysis of the Fusarium graminearum species complex from wheat, barley and maize in South Africa provides evidence of species-specific differences in host preference. Fungal Genet Biol 48:914-920

Brown DW, Butchko RA, Busman M, Proctor RH (2012) Identification of gene clusters associated with fusaric acid, fusarin, and perithecial pigment production in Fusarium verticillioides. Fungal Genet Biol 49:521-532

de Oliveira Rocha L, Reis GM, da Silva VN, Braghini R, Teixeira MMG, Corrêa B (2011) Molecular characterization and fumonisin production by Fusarium verticillioides isolated from corn grains of different geographic origins in Brazil. Int J Food Microbiol $145: 9-21$

Desjardins AE (2006) Fusarium mycotoxins: chemistry, genetics, and biology. American Phytopathological Society, St. Paul, MN

Edgar RC (2004) MUSCLE: a multiple sequence alignment method with reduced time and space complexity. BMC Bioinformatics 5:113

Gouy M, Guindon S, Gascuel O (2010) SeaView version 4: a multiplatform graphical user interface for sequence alignment and phylogenetic tree building. Mol Biol Evol 27:221-224

Haas BJ, Zeng Q, Pearson MD, Cuomo CA, Wortman JR (2011) Approaches to fungal genome annotation. Mycology 2:118-141

Hatsch D, Phalip V, Jeltsch J-M (2004) Use of genes encoding cellobiohydrolase-C and topoisomerase II as targets for phylogenetic analysis and identification of Fusarium. Res Microbiol 155:290-296

Jacobs A, Van Wyk PS, Marasas WFO, Wingfield BD, Wingfield MJ, Coutinho TA (2010) Fusarium ananatum sp. nov. in the Gibberella fujikuroi species complex from pineapples with fruit rot in South Africa. Fungal Biol 114:515-527

Jurado M, Marín P, Callejas C, Moretti A, Vázquez C, González-Jaén MT (2010) Genetic variability and fumonisin production by $\mathrm{Fu}$ sarium proliferatum. Food Microbiol 27:50-57

Kenényi Z, Mulé G, Moretti A, Waalwijk C, Hornok L (2002) Fertility and mating type assessment within Fusarium proliferatum isolates from different host plants. J Appl Genet 43A:55-68

Khaldi N, Wolfe KH (2011) Evolutionary origins of the fumonisin secondary metabolite gene cluster in Fusarium verticillioides and Aspergillus niger. Int J Evol Biol 2011:423821

Kostecki M, Wiśniewska H, Perrone G, Ritieni A, Goliński P, Chełkowski J, Logrieco A (1999) The effects of cereal substrate and temperature on production of beauvericin, moniliformin and fusaproliferin by Fusarium subglutinans ITEM-1434. Food Addit Contam 16:361-365

Kristensen R, Torp M, Kosiak B, Holst-Jensen A (2005) Phylogeny and toxigenic potential is correlated in Fusarium species as revealed by partial translation elongation factor 1 alpha gene sequences. Mycol Res 109:173-186

Kvas M, Marasas WFO, Wingfield BD, Wingfield MJ, Steenkamp ET (2009) Diversity and evolution of Fusarium species in the Gibberella fujikuroi complex. Fungal Divers 34:1-21

Larkin MA, Blackshields G, Brown NP, Chenna R, McGettigan PA, McWilliam H, Valentin F, Wallace IM, Wilm A, Lopez R, Thompson JD, Gibson TJ, Higgins DG (2007) Clustal W and Clustal X version 2.0. Bioinformatics 23:2947-2948

Leslie JF, Summerell BA (2006) The Fusarium laboratory manual. Wiley-Blackwell, Hoboken, NJ
Lievens B, Claes L, Vakalounakis DJ, Vanachter ACRC, Thomma BPHJ (2007) A robust identification and detection assay to discriminate the cucumber pathogens Fusarium oxysporum f. sp. cucumerinum and f. sp. radicis-cucumerinum. Environ Microbiol 9:2145-2161

Marchler-Bauer A, Lu S, Anderson JB, Chitsaz F, Derbyshire MK, DeWeese-Scott C, Fong JH, Geer LY, Geer RC, Gonzales NR, Gwadz M, Hurwitz DI, Jackson JD, Ke Z, Lanczycki CJ, Lu F, Marchler GH, Mullokandov M, Omelchenko MV, Robertson CL, Song JS, Thanki N, Yamashita RA, Zhang D, Zhang N, Zheng C, Bryant SH (2011) CDD: a Conserved Domain Database for the functional annotation of proteins. Nucleic Acids Res 39:D225D229

Moretti A, Mulé G, Ritieni A, Láday M, Stubnya V, Hornok L, Logrieco A (2008) Cryptic subspecies and beauvericin production by Fusarium subglutinans from Europe. Int J Food Microbiol 127:312-315

Nicholson P, Simpson DR, Wilson AH, Chandler E, Thomsett M (2004) Detection and differentiation of trichothecene and enniatin-producing Fusarium species on small-grain cereals. Eur J Plant Pathol 110:503-514

O’Donnell K, Ward TJ, Geiser DM, Corby Kistler H, Aoki T (2004) Genealogical concordance between the mating type locus and seven other nuclear genes supports formal recognition of nine phylogenetically distinct species within the Fusarium graminearum clade. Fungal Genet Biol 41:600-623

Pel HJ, de Winde JH, Archer DB, Dyer PS, Hofmann G, Schaap PJ, Turner G, de Vries RP, Albang R, Albermann K, Andersen MR, Bendtsen JD, Benen JA, van den Berg M, Breestraat S, Caddick MX, Contreras R, Cornell M, Coutinho PM, Danchin EG, Debets AJ, Dekker P, van Dijck PW, van Dijk A, Dijkhuizen L, Driessen AJ, d'Enfert C, Geysens S, Goosen C, Groot GS, de Groot PW, Guillemette T, Henrissat B, Herweijer M, van den Hombergh JP, van den Hondel CA, van der Heijden RT, van der Kaaij RM, Klis FM, Kools HJ, Kubicek CP, van Kuyk PA, Lauber J, Lu X, van der Maarel MJ, Meulenberg R, Menke H, Mortimer MA, Nielsen J, Oliver SG, Olsthoorn M, Pal K, van Peij NN, Ram AF, Rinas U, Roubos JA, Sagt CM, Schmoll M, Sun J, Ussery D, Varga J, Vervecken W, van de Vondervoort PJ, Wedler H, Wösten HA, Zeng AP, van Ooyen AJ, Visser J, Stam H (2007) Genome sequencing and analysis of the versatile cell factory Aspergillus niger CBS 513.88. Nat Biotechnol $25: 221-231$

Ploetz RC (2001) Significant diseases in the tropics that are caused by species of Fusarium. In: Fusarium: Paul E. Nelson Memorial Symposium. The American Phytopathological Society Press, St. Paul, MN, pp 295-309

Ploetz RC (2006) Fusarium-induced diseases of tropical, perennial crops. Phytopathology 96:648-652

Proctor RH, Desjardins AE, Plattner RD, Hohn TM (1999) A polyketide synthase gene required for biosynthesis of fumonisin mycotoxins in Gibberella fujikuroi mating population A. Fungal Genet Biol 27:100-112

Proctor RH, Plattner RD, Desjardins AE, Busman M, Butchko RAE (2006) Fumonisin production in the maize pathogen Fusarium verticillioides: genetic basis of naturally occurring chemical variation. J Agric Food Chem 54:2424-2430

Proctor RH, Busman M, Seo J-A, Lee YW, Plattner RD (2008) A fumonisin biosynthetic gene cluster in Fusarium oxysporum strain $\mathrm{O}-1890$ and the genetic basis for B versus C fumonisin production. Fungal Genet Biol 45:1016-1026

Punja ZK, Wan A, Rahman M, Goswami RS, Barasubiye T, Seifert KA, Lévesque CA (2008) Growth, population dynamics, and diversity of Fusarium equiseti in ginseng fields. Eur J Plant Pathol 121:173-184 
Rohrbach KG, Pfeiffer JB (1976) Susceptibility of pineapple cultivars to fruit diseases incited by Penicillium funiculosum and Fusarium moniliforme. Phytopathology 66:1386-1390

Sayers EW, Barrett T, Benson DA, Bolton E, Bryant SH, Canese K, Chetvernin V, Church DM, Dicuccio M, Federhen S, Feolo M, Fingerman IM, Geer LY, Helmberg W, Kapustin Y, Krasnov S, Landsman D, Lipman DJ, Lu Z, Madden TL, Madej T, Maglott DR, Marchler-Bauer A, Miller V, Karsch-Mizrachi I, Ostell J, Panchenko A, Phan L, Pruitt KD, Schuler GD, Sequeira E, Sherry ST, Shumway M, Sirotkin K, Slotta D, Souvorov A, Starchenko G, Tatusova TA, Wagner L, Wang Y, Wilbur WJ, Yaschenko E, Ye J (2012) Database resources of the National Center for Biotechnology Information. Nucleic Acids Res 40:D13-D25

Scauflaire J, Gourgue M, Munaut F (2011) Fusarium temperatum sp. nov. from maize, an emergent species closely related to Fusarium subglutinans. Mycologia 103:586-597

Stankovic S, Levic J, Petrovic T, Logrieco A, Moretti A (2007) Pathogenicity and mycotoxin production by Fusarium proliferatum isolated from onion and garlic in Serbia. Eur J Plant Pathol 118:165-172

Steenkamp ET, Wingfield BD, Coutinho TA, Wingfield MJ, Marasas WFO (1999) Differentiation of Fusarium subglutinans f. sp. pini by histone gene sequence data. Appl Environ Microbiol 65:34013406

Stępien $\_$(2013) The use of Fusarium secondary metabolite biosynthetic genes in chemotypic and phylogenetic studies. Crit Rev Microbiol. doi:10.3109/1040841X.2013.770387

Stępień $Ł$, Waśkiewicz A (2013) Sequence divergence of the enniatin synthase gene in relation to production of beauvericin and enniatins in Fusarium species. Toxins (Basel) 5:537-555

Stępień $Ł$, Chełkowski J, Wenzel G, Mohler V (2004) Combined use of linked markers for genotyping the $\mathrm{Pml}$ locus in common wheat. Cell Mol Biol Lett 9:819-827

Steppień Ł, Koczyk G, Waśkiewicz A (2011a) FUM cluster divergence in fumonisins-producing Fusarium species. Fungal Biol 115:112123

Stępień Ł, Koczyk G, Waśkiewicz A (2011b) Genetic and phenotypic variation of Fusarium proliferatum isolates from different host species. J Appl Genet 52:487-496
Stępień Ł, Gromadzka K, Chełkowski J (2012) Polymorphism of mycotoxin biosynthetic genes among Fusarium equiseti isolates from Italy and Poland. J Appl Genet 53:227-236

Sutherland ML, Pegg GF (1992) The basis of host recognition in Fusarium oxysporum f. sp. lycopersici. Physiol Mol Plant Pathol 40:423-436

Tamura K, Dudley J, Nei M, Kumar S (2007) MEGA4: Molecular Evolutionary Genetics Analysis (MEGA) software version 4.0. Mol Biol Evol 24:1596-1599

Thiel PG, Marasas WFO, Sydenham EW, Shephard GS, Gelderblom WC (1992) The implications of naturally occurring levels of fumonisins in corn for human and animal health. Mycopathologia 117:3-9

von Bargen S, Martinez O, Schadock I, Eisold A-M, Gossmann M, Büttner C (2009) Genetic variability of phytopathogenic Fusarium proliferatum associated with crown rot in Asparagus officinalis. J Phytopathol 157:446-456

Waalwijk C, van der Lee T, de Vries I, Hesselink T, Arts J, Kema GHJ (2004) Synteny in toxigenic Fusarium species: the fumonisin gene cluster and the mating type region as examples. Eur J Plant Pathol 110:533-544

Waśkiewicz A, Goliński P, Karolewski Z, Irzykowska L, Bocianowski J, Kostecki M, Weber Z (2010) Formation of fumonisins and other secondary metabolites by Fusarium oxysporum and $F$. proliferatum: a comparative study. Food Addit Contam 27:608615

Watanabe M, Yonezawa T, Lee K, Kumagai S, Sugita-Konishi Y, Goto K, Hara-Kudo Y (2011) Molecular phylogeny of the higher and lower taxonomy of the Fusarium genus and differences in the evolutionary histories of multiple genes. BMC Evol Biol 11:322

Weber Z, Kostecki M, von Bargen S, Gossmann M, Waskiewicz A, Bocianowski J, Knaflewski M, Büttner C, Golinski P (2006) Fusarium species colonizing spears and forming mycotoxins in field samples of Asparagus from Germany and Poland. J Phytopathol 154:209-216

Zhang T, Jia X, Zhuo Y, Liu M, Gao H, Liu J, Zhang L (2012) Cloning and characterization of a novel 2-ketoisovalerate reductase from the beauvericin producer Fusarium proliferatum LF061. BMC Biotechnol 12(55):1-9 